\title{
Evaluating the relative influence on population health of domestic gardens and green space along a rural-urban gradient
}

\begin{abstract}
Studies have repeatedly affirmed the positive links between human and environmental health but few have sufficiently addressed the complexity brought about by the range of urbanity, population and both green space and domestic gardens cover associated human settlements. With the global population increasingly residing in cities, the relevance of urbanisation, local population and discrete types of green space provision on measures of health, remains a research imperative. To explore this complexity, a series of regression models were employed to quantify the mitigation of local health deprivation by green space and domestic gardens, across a four-stage rural-urban gradient, controlling for household income and local population. The population-standardised quantification of green space provision offered greater interpretive power than did a simple measure of land cover density. Domestic gardens, of the two green land-cover types, provided the most convincing mitigating effect on health deprivation. The findings call for increased acknowledgement of urban gardens in local health promotion, and a closer consideration of local population in planning green space provision and management.
\end{abstract}

\section{Introduction}

The links between the natural environment and human health have taken a central role in approaches to natural resource management since the launch of the Ecosystem Approach (CBD, 2004). In particular, Principle 5 of the Ecosystem Approach, which promotes the conservation of ecosystem function towards the maintenance of services vital to human well-being, was taken up in earnest by the Millennium Ecosystem Assessment (MEA, 2005). The ecosystem services framework has since become a ubiquitous ingredient in social-ecological research (Constanza et al., 2006; Constanza et al., 2007; De Groot et al., 2002; Mace et al., 2012; Niemelä et al., 2010; Tyrvainen, 2001; Wall and Nielsen, 2012) and has taken a central role in efforts to influence the nurturing of positive human-environmental relationships through policy (Defra, 2010; 2011; Haines-Young and Potschin, 2013; MEA, 2005; TEEB, 2008; UK NEA, 2011;).

A variety of services have been identified as relevant to human health. These cover the regulating, provisioning, supporting, and cultural ecosystem services (Millennium Ecosystem Assessment classification: MEA, 2005). Many of these services are concerned with the production of indirect-use goods and services such as food production, air purification, water attenuation and filtration, soil formation and pollination (De Groot et al., 2010) and the primary focus of the Millennium Ecosystem Assessment involved an investigation into the importance of such services for human well-being and poverty alleviation, particularly in developing countries and the Global South. In addition to services directly related to human subsistence, a number of so-called non-use value services relate to human experience and interaction with nature itself (De Groot et al., 2010; Niemelä et al., 2010). The majority of such benefits of natural environments are described as cultural ecosystem services primarily appreciated for their aesthetic and recreational value (Haines-Young and Potschin, 2013; MEA, 2005; Niemelä et al., 2010; UK NEA, 2011). Increasingly, however, the importance of activity in and proximity to nature, mediated by such factors as aesthetics (Galindo and Corraliza, 2000), biodiversity (Fuller et al., 2007) and recreation (Bird, 2007) have been proven to be beneficial to human health (Carrus et al., 2015; Tzoulas et al., 2007). Research into the importance of exposure to nature for human well-being (Carrus et al., 2015; Fuller et al., 2007; Krasny and Tidball, 2015; Maas et al., 2009; Mitchell et al., 2011; Pretty et al., 2005), has gained increasing momentum towards the understanding and promotion of health in urban populations, particularly in urban centres of the Global North, the context of the current study. 
With the majority of the global population now residing in towns and cities (United Nations, 2007), attention has turned to the ecological conditions which influence human health in the urban environment (Bolund and Hunhammar, 1999; Coutts, 2011; MEA, 2005; WHO, 2005;). Although urban areas appropriate vast ecological resources, relying on ecosystem services generated at much wider scales (Folke et al., 1997), quality of life for urban residents is also highly dependent on natural elements within cities (Krasny and Tidball, 2015; MEA, 2005; Stott et al., 2015; UK NEA, 2011). Studies have repeatedly shown the positive effects on the well-being of urban inhabitants stemming from naturalistic environments in cities (Burls, 2005; Mitchell and Popham, 2007; Niemelä et al., 2010; Tzoulas et al., 2007; Von Shirnding, 2002). In attempts to understand the dynamic between urban green space and human physical and mental health, much of the research carried out has explored correlations between measures of self-reported health and environmental factors such as living in proximity to green space (Jackson, 2003; Gidlöf-Gunnarsson and Öhrström, 2007; Kaplan, 1995; Maas et al., 2006; Maas et al., 2009; Maller et al., 2006), local access to naturalistic areas (Ward Thompson et al., 2014) and physical activity in nature (Bird, 2007; Carrus et al., 2015; Marselle et al., 2014; Pretty et al., 2005; Tzoulas et al., 2007). The measured health-related outcomes include reduced levels of morbidity (Mitchell and Popham, 2008), stress reduction (Macdonald, 1994), attention restoration (Li and Sullivan, 2016; Sullivan and Chang, 2011; Taylor et al., 2002) and increased social (Sullivan et al., 2004) and physical (Epstein et al., 2006) activity.

Notwithstanding the insight gained from such work, few studies have given sufficient attention to the effect of increasing urbanity itself on human well-being. Some investigations have attempted to quantify the impact of increasing urbanisation on ecosystem services through the use of spatial analyses across a rural-urban gradient (Radford and James, 2013). However, such work does not directly explore the accumulative influence of urbanisation on resident well-being through specifically health-related datasets. The latter have been effectively employed in previous studies into the effects of green space and human health (e.g. Maas et al., 2009; Mitchell and Popham, 2007; Mitchell et al., 2011) but these have in turn largely neglected the relevance of rural to urban transitions.

Mitchell and Popham (2007) investigated the effect of green space at discrete levels of both physical (urbanity) and socio-economic (household income) characteristics but employed a simplistic typology of urbanity which failed to reflect the range of urbanisation occurring along a rural-urban gradient. Moreover, such studies have not accounted for levels of human population in their assessments of green space provision, primarily taking percentage land cover as a standardised measure. Given that increasing urbanity is, by definition, accompanied by increasing human population, detailed investigations into the relationship between human health and green space would benefit from integrating local population data into their methodologies.

Although the therapeutic effects of biodiverse spaces have been well documented (Carrus et al., 2015; Marcus and Sachs, 2013; Tzoulas et al., 2007), much of the work investigating the reciprocity of human-environmental health has focussed specifically on green space and neglected the role of urban gardens, despite the latter being presented as highly biodiverse elements in urban ecosystems (Cameron et al., 2012; Clark and Jenerette, 2014; Goddard et al., 2010; Orsini et al., 2014; Taylor et al., 2016; Thompson et al., 2003). Furthermore, studies have compared the ecological quality of domestic and community gardens with that of other green space types such as city parks (Barthel et al., 2010; Speak et al., 2015), emphasising the greater value of the former in terms of species richness. Despite these claims, research into the relative benefits of domestic and green space towards measures of human health is currently lacking. Mitchell et al. (2011) concluded that larger areas of green space were of most importance in terms of health promotion in urban landscapes but did not discriminate between green space and more compact domestic gardens types. The same view, and shortcoming, is evident in Stott et al. (2015) where larger parks and reserves were promoted as being crucial for ecosystem service provision and, therefore, well-being among urban 
inhabitants. Again, no distinction was made here between the differential benefits stemming from public and domestic gardens types. Francis (1987) observed that there are significant differences in the physical activities which take place in communal gardens and larger areas of green space such as city parks. Moreover, horticultural practices in communal gardens involved greater levels of physical activity and interaction with ecological processes suggesting that such spaces may be particularly beneficial to health (Francis, 1987). Horticulture-based activities have been championed in other research due to their potential for improving the physical and mental health of practitioners (Perrins-Margalis et al., 2000; Hynes and Howe, 2004; Pudup, 2008; Krasny and Tidball, 2015) the particular effect of domestic gardens on human health in cityscapes warrants closer attention in epidemiological studies into health in the urban environment. The benefits of gardens and gardening to well-being are considered so effective that the design of "healing" gardens has become a topic of research in itself and a credible ingredient to patient convalescence in health care situations (Marcus and Sachs, 2013). The restorative influence of gardens has been well demonstrated in hospital settings (Söderback et al., 2004; Marcus, 2007) but also in other environments such as educational institutions (Lau and Yang, 2009) and places of work (Lottrup et al., 2013). They have also been presented as significant in more cultural forms of healing such as conflict resolution (Krasny and Tidball, 2015), promoting individual and wider social education and transformation (Pudup, 2008), and social cohesion (Kuo et al., 1998; Kuo and Sullivan, 2001; Okvat and Zautra, 2011).

To address the absence of knowledge on the relative effects of green space and domestic gardens on human health, a comparison of the relationships between both domestic gardens and green space on local health across a rural-urban gradient was conducted in the north-west of England, UK. This region of the United Kingdom includes a wide range of habitats across the full range of possible levels of urbanity, from mountainous areas of national parkland to coastal regions to highly urbanised centres in the form of some of the oldest industrialised metropolises in the world (Kidd, 2006). The region thereby provided a considerable and appropriate dataset with which to explore the relationship between green space and domestic gardens types with public health at discrete levels of urbanisation.

\section{Methods}

\section{Overview}

A comparison of the relative effect of both domestic gardens and public green on local levels of health, by multiple regression, was conducted along a four-stage rural-urban gradient in North West England, defined as the Government Office Region boundary for this area (ONS, 2001). The mediating effect of local population on green space provision at different levels of urbanity was also factored in to the analysis. Secondary data were obtained from UK government statistics sources. Land cover data were downloaded from Office for National Statistics (ONS, 2005), area deprivation data from the Department of Communities and Local Government database (DCLG, 2010) and population data from 2001 census records via the UK Data Service (ONS, 2001). All three datasets were based on pre-2011 UK census population and geographical data. The more recent 2011 UK census coincided with the re-alignment of a number of administrative boundaries. One of the implications of this re-alignment was that census data were incongruous with published data on green space and population health. Therefore, compatible pre-2011 datasets were used in the analysis. Data were treated as follows:

\section{Land cover data}

Data on land-cover were obtained from the UK Office for National Statistics' Generalised Land Use Database (GLUD: ONS, 2005). The database classifies areas at a range of geographical units into nine discrete built and green land use types in units of $1000 \mathrm{~m}^{2}$ based on land features extracted from the 
Ordnance Survey OS Mastermap (ONS, 2001). The nine land land use classifications included in the GLUD are: domestic buildings, non-domestic buildings, green space, domestic gardens, open water, roads, paths, rail and a final category encompassing "other" land-uses, largely comprising hardstanding surfaces. These data were used to characterise the study area region by calculating the percentage cover of green space and domestic gardens. Within the GLUD the former includes green land cover designated as public spaces (including parks, communal gardens and cemeteries) and agricultural land. Conversely, domestic gardens are classified as parcels of land annexed by residential buildings (housing either single or multiple families and individuals). Data were extracted for the lowest geographical scale for UK administrative boundary data: lower layer super output areas (LSOAs). These geographical units are employed by the UK government to generate and disseminate small area statistics and are defined as areas with populations of between 1,000 and 3,000 persons, and between 400 and 1,200 households (ONS, 2016). Given this basis of determination, LSOAs by definition have comparable population and numbers of households. Accordingly, along a rural-urban gradient, the geographical area of LSOAs varies relative to population density (see Table 1).

All LSOAs within the study area were categorised into four discrete levels of urbanity (rural, periurban, suburban and urban). Measures of urbanity were founded on the proportion of land cover by total green space. The four stages of a rural-urban gradient were calculated by separating LSOAs into quartiles on the basis of percentage total green space cover. Mean levels of specifically green space and domestic gardens were then compared across the four levels of urbanisation. Given that population density can be expected to vary at different stages of urbanisation, a second measure of green space provision was calculated which took the local population into account. The latter were obtained from the UK Data Service as of the 2001 census. Subsequently, green space and domestic garden cover at different levels of urbanisation were compared as values of area cover expressed as $\mathrm{m}^{2}$ person ${ }^{-1}$. Basic statistics on population and land cover characteristics for LSOAs in the study area across the four stages of the land cover derived rural-urban gradient are presented in Table 1.

Table 1. Urban-rural gradient in North West England: LSOA basic statistics

\begin{tabular}{|llrrr|}
\hline \multirow{2}{*}{ Gradient Stage } & Total area (ha) & Population & $\begin{array}{c}\text { Total green land } \\
\text { cover (\%) }\end{array}$ \\
\hline Urban & Mean & 106.26 & 1510 & 38.50 \\
\cline { 2 - 5 } & SD & 561.88 & 176 & 10.69 \\
\hline Suburban & Mean & 48.48 & 1509 & 59.77 \\
\cline { 2 - 5 } & SD & 141.90 & 141 & 3.42 \\
\hline Peri-urban & Mean & 75.97 & 1497 & 71.21 \\
\cline { 2 - 5 } & SD & 300.66 & 161 & 3.95 \\
\hline Rural & Mean & 1102.23 & 1521 & 58.39 \\
\cline { 2 - 5 } & SD & 2656.44 & 253 & 64.47 \\
\hline Total & Mean & 333.11 & 1509 & 19.27 \\
\cline { 2 - 5 } & SD & 1437.42 & 188 & \\
\hline
\end{tabular}

\section{Area deprivation data}

In order to explore the relationship between local levels of health and green space types, data on local levels of deprivation were taken from the 2010 Index of Multiple Deprivation (IMD: DCLG, 2010), following established methods of investigation (Mitchell and Popham, 2007; Woods et al., 
2005). The IMD is built from thirty-eight separate indicators derived from UK census data across seven distinct domains relating to discrete forms of social deprivation. The seven domains are: Income Deprivation, Employment Deprivation, Health Deprivation and Disability, Education Skills and Training Deprivation, Barriers to Housing and Services, Living Environment Deprivation, and Crime.

The sub-domains health deprivation and income deprivation were obtained for each LSOA in the study area. The indicators for health deprivation as employed in the IMD are: years of potential life lost, comparative illness and disability ratio, acute morbidity and mood and anxiety disorders. For each indicator in the health deprivation sub-domain, a denominator (based on mid-year population estimates) seeks to measure the number of people (or households) that are 'at-risk' of being defined as deprived. Factor analysis is then applied to assign weights to each indicator resulting in a final score as a dimensionless measure of deprivation within each sub-domain relative to other LSOAs in the dataset. The resulting data, as a composite score reflecting levels of overall health deprivation, were obtained from the UK government open data archive (DCLG , 2010) and entered into SPSS.20 for statistical analysis.

\section{Analysis}

These data were then used to explore the relative effect of green space and domestic gardens on health deprivation through multiple regression analysis. This latter domain was entered as the dependent variable into four separate multiple regression analyses according to the four degrees of urbanity (rural, peri-urban, suburban and urban) with the two green space types entered as independent variables. In all cases, data on income deprivation were also entered into the multiple regression as an independent variable in order to control for the effects of income which may result in confounding the relationship between green space types and health.

The model thereby allowed for a detailed exploration of the differential effects of domestic gardens and green space on local health at various levels of urbanity. Calculating green space and domestic garden cover standardised by local population also offered an effective means to evaluate differential distribution both in terms of percentage cover by the two land cover types as well as provision as area cover person ${ }^{-1}$ as a mediating co-variable.

\section{Results and Discussion}

The separation of green land-cover into green space and domestic gardens revealed differential patterns of cover across the rural-urban gradient employed in the study as presented in Figure 1. 


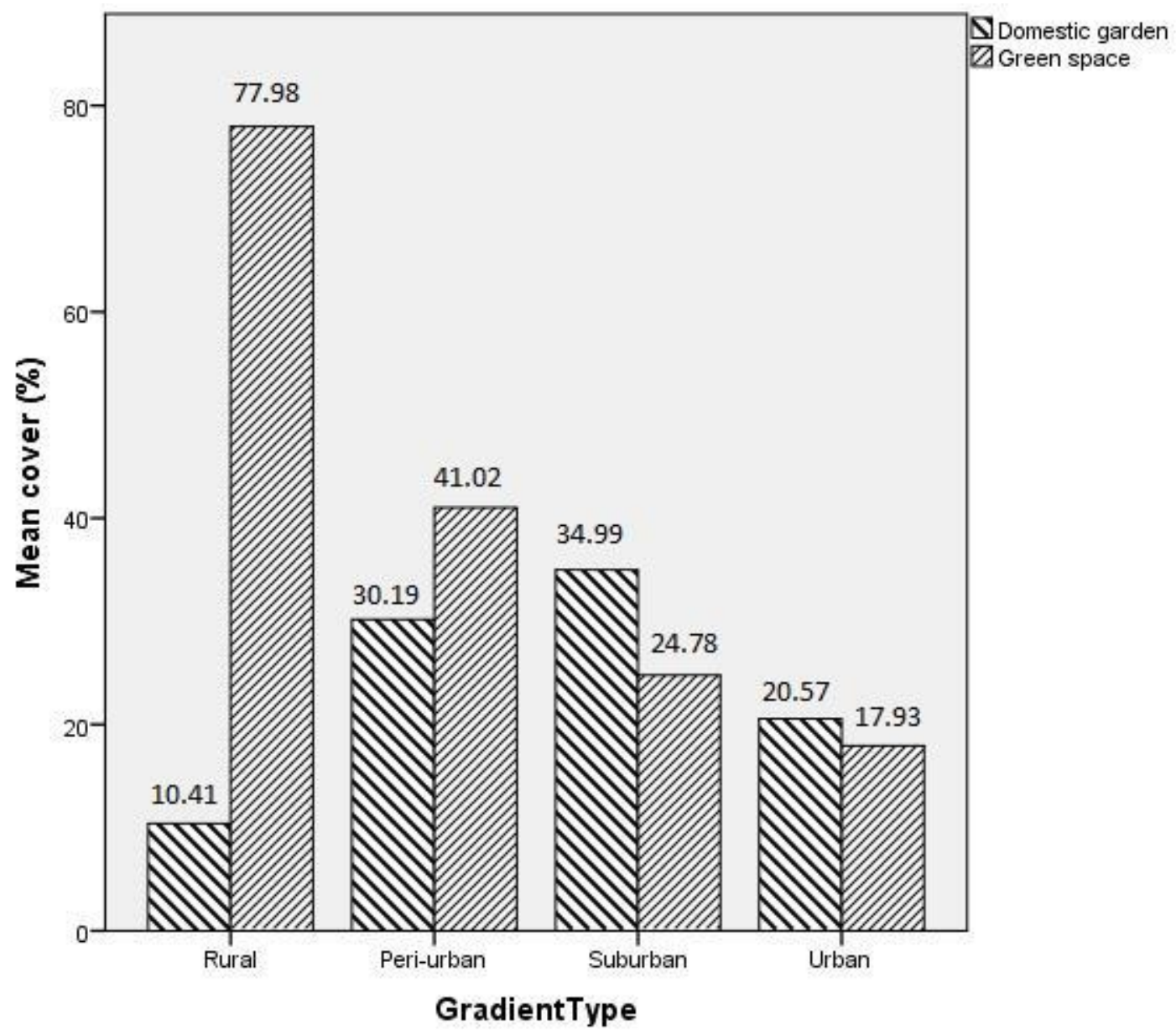

Figure 1. Extent (mean percentage of total LSOA area) of domestic gardens and green space across the four stages of urbanisation in North West England.

The results of the four-stage multiple regression analysis are presented in Table 2.

Table 2: Results of the four-stage multiple regression model, regressing health deprivation and disability score on income deprivation score, garden cover, and green space area across four stages of urbanisation in North West England

\begin{tabular}{|c|c|c|c|c|c|c|c|}
\hline \multirow[b]{2}{*}{ Model } & \multicolumn{3}{|c|}{$\begin{array}{l}\text { Standardized } \\
\text { Coefficients }\end{array}$} & \multirow[b]{2}{*}{ Sig. } & \multicolumn{3}{|c|}{ Correlations } \\
\hline & Urban & Beta & $T$ & & Zero-order & Partial & Part \\
\hline & Income dep. & 0.795 & 44.837 & $<0.001$ & 0.812 & 0.803 & 0.778 \\
\hline & Garden cover & -0.102 & -4.882 & $<0.001$ & -0.223 & -0.145 & -0.085 \\
\hline & Green space & -0.057 & -2.777 & 0.006 & 0.029 & -0.083 & \begin{tabular}{|c|}
-0.048 \\
\end{tabular} \\
\hline Model & Suburban* & & & & & & \\
\hline & Income dep. & 0.855 & 57.478 & $<0.001$ & 0.872 & 0.865 & 0.836 \\
\hline & Garden cover & -0.078 & -5.267 & $<0.001$ & -0.258 & -0.156 & -0.077 \\
\hline Model & Peri-urban & & & & & & \\
\hline & Income dep. & 0.838 & 57.065 & $<0.001$ & 0.877 & 0.863 & 0.796 \\
\hline & Garden cover & -0.444 & -7.106 & $<0.001$ & -0.325 & -0.208 & -0.099 \\
\hline & Green space & -0.359 & -5.810 & $<0.001$ & 0.270 & -0.171 & -0.081 \\
\hline Model & Rural & & & & & & \\
\hline & Income dep. & 0.718 & 37.849 & $<0.001$ & 0.786 & 0.751 & 0.672 \\
\hline
\end{tabular}




\begin{tabular}{|lrrrrrr|}
\hline Green space & -0.668 & -10.185 & $<0.001$ & -0.117 & -0.292 & -0.181 \\
\hline Garden cover & -0.645 & -9.865 & $<0.001$ & -0.013 & -0.284 & -0.175 \\
\hline
\end{tabular}

*Green space removed from model at $p=0.290$

\section{Measures of green space provision and mitigation of health deprivation}

The relative benefits of green space and domestic gardens as environmental buffers against health deprivation varied significantly across the rural-urban gradient defined in the study area. Although both land-cover variables bore a negative relationship overall with measures of health deprivation, demonstrating their positive contribution to the health of local residents, both green space types exhibited decreasing effect sizes on the health deprivation from rural to suburban areas, with the strength of the relationship recovering to a degree in the most urban quartile of the study area. This parallel in effect size was not mirrored however in the respective change in land-cover across the rural-urban gradient. Whereas green space cover fell linearly with increasing urbanisation, dropping sequentially through the four levels of urbanity, mean domestic garden cover exhibited the inverse pattern, increasing from the rural to suburban zones before dropping sharply in the most urban areas. Although this latter area category was associated with the lowest level of cover of both green space types, it did not exhibit the lowest Beta co-efficients in the regression, thereby bucking the overall trend presented in the analysis. The weakest relationships between green space and health were in fact associated with suburban areas (Table 2). In this latter category, there was no significant association between green space and local measures of health deprivation and with domestic gardens only a weak effect was exhibited (Table 2) despite garden cover being at its highest in this category of urbanity. The high levels of domestic garden cover in such areas reflect an increase in population and density of households relative to other urban types, as denoted by lower mean LSOA size for this category (see Table 1). Such relative increases in population density, whilst bringing about a net gain in domestic garden cover, may also result in smaller gardens per household or a greater number of residences without gardens.

Moving into the most urban areas of the study, the effect of both green land cover types increases despite both decreasing in terms of percentage cover relative to suburban areas. This shift from suburban to urban areas suggests that, in the latter, green space takes on greater significance relative to the former in terms of its influence on the health of local residents, perhaps due to an increase in provision per person (Figure 2). However here and at all levels of urbanity, with the exception of the most rural zone in the study, the mitigating effect of domestic gardens as opposed to green space was greater. The alternative population-standardised measure of green space provision across the rural-urban gradient, as hectares person ${ }^{-1}$ added greater detail to this element of the analysis and is presented in Figure 2. 


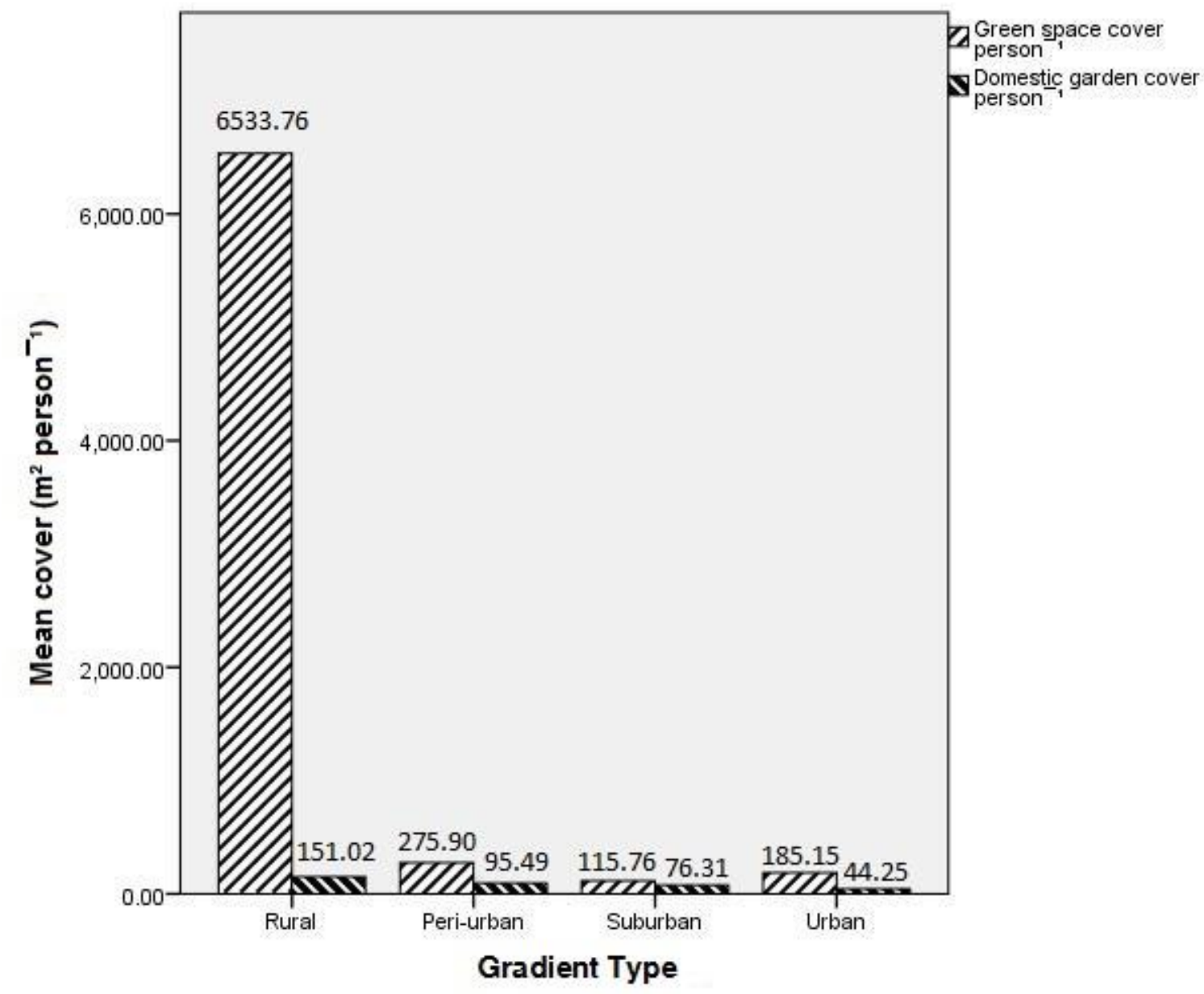

Figure 2. Green space and domestic garden provision (as area cover in $\mathrm{m}^{2}$ person ${ }^{-1}$ ) across the four levels of urbanisation in North West England.

The population-standardised measure of domestic and green space provision, as area cover person $^{-1}$, presented a markedly different pattern of distribution across the four levels of urbanity explored. The greatest disparity in this version of the comparison was exhibited within the rural land cover category in which green space provision per person outnumbered its domestic counterpart by a factor of more than thirty. The extreme polarity between domestic gardens and green space in the rural quartile of the study is a result of the way in which lower super output areas (LSOAs) are defined by the UK Office for National Statistics census geography. In this classification system such areas contain a minimum population of 1,000 people and number no fewer than 400 households (ONS, 2016). In the most rural regions of the study area, LSOAs may extend over considerable areas of land in order to conform to the minimum population and household counts, resulting in their covering relatively vast areas of rural green space and thereby providing large areas of green space person ${ }^{-1}$.

Although occurring in considerably lower abundance in all other gradient categories, green space nevertheless exhibited greater area cover relative to local population than did domestic gardens. The variation in green space distribution produced by the population-standardised measure of provision followed more closely that of the regression co-efficients along the rural-urban gradient than did the measure of overall percentage cover. In the case of green space, the level of provision per person decreased from rural to suburban areas, subsequently recovering moving into the most urbanised quartile of the study area. This trend mimicked that of the corresponding Beta coefficients which described the strength of the relationship between green space and health. 
In terms of domestic garden cover this second measure of provision, controlling for population, clarified to some degree the drop in contribution of this land cover type to local health. Due to increasing population from rural to suburban areas, domestic garden cover, although increasing overall, decreased in terms of actual provision per resident resulting in a weaker mitigating effect on health deprivation (Table 2). Notwithstanding this pattern from rural to suburban areas, the influence of domestic gardens increased in areas of highest urbanity despite a reduction in cover relative to population (Figure 2). It may be the case that in such highly urban zones, residents make more use of the little domestic garden space available to them, perhaps due to issues surrounding quality and access to local green space.

The analysis suggests therefore, that measures of green space which take into account local population offer greater explanatory power in terms of describing the relationship between green spaces and health than do simple measures of percentage land cover. This is a consideration which has escaped sufficient attention in previous study and planning of urban environments.

\section{Relative effects of green space and domestic gardens on local measures of human health}

The mitigating effect of domestic gardens on local area health deprivation was greater than that of green space at all levels of urbanity other than the most rural. However, even within this rural category of land-cover, green space and domestic gardens presented comparable beta co-efficients (Table 1), despite the latter accounting for less than ten percent of total green land cover. In periurban areas, which also contained lower mean land-cover by domestic gardens, this latter green space type had a significantly greater effect as a buffer against health deprivation (Table 2). Furthermore the effect sizes in the regression model associated with domestic gardens, although diminishing in suburban and urban areas, were, relative to that of green space, even greater than in more rural locations.

The variance in green space provision from a local population-based perspective appeared to provide even greater support for domestic gardens as a buffer against levels of poor health. From such an orientation, domestic garden cover was lower in abundance than green space at all stages of the rural-urban gradient. Again, here rural areas exhibited the greatest disparity between domestic garden and green space cover and the regression statistics demonstrated that the former exerted a comparable influence on local health whilst only reflecting a small fraction of the provision person ${ }^{-1}$ exhibited by the latter.

Not only does this reinforce the case for the relative efficacy of specifically domestic gardens but suggests that the influence of green space may plateau above certain thresholds in either percentage cover or cover person ${ }^{-1}$. Although mean values for both percentage cover and cover person $^{-1}$ in rural areas were many factors greater than those in the peri-urban category, the respective Beta co-efficient associated with green space in the regression model in the former was less than fifty percent greater than that in the latter. Accordingly the analyses suggest that, above a certain level of abundance, the power of green space to buffer against levels of poor health does not differ significantly. Furthermore, similar benefits may be derived from considerably lower levels of domestic garden cover person ${ }^{-1}$.

A shortcoming of the analysis arises from the fact that the measure of green space provided by the GLUD included communally managed gardens. Such spaces may resemble domestic gardens in terms of management and use, confounding a reasonable comparison, or conversely, they may offer entirely different activities and experiences to either domestic gardens or more general green space types (Francis, 1987; Guitart et al., 2012; Pudup, 2008). Notwithstanding the problems of categorisation, previous studies into the distribution (Dennis et al., 2016a; 2016b) of collectively 
managed pockets of green space throughout an urban zone within current study area provided an estimate of land cover by such spaces as comprising $<0.05 \%$ of total green space. Given this proportionally negligible representation of the total by communally managed spaces, the inclusion of the latter in the GLUD green space category is unlikely to have had any significant bearing on the output of regression analyses employed herein.

Although land cover by such spaces was minimal, other studies in the same geographical context (Dennis and James 2016a; 2016b) have presented community gardens, allotments and orchards as highly productive spaces in terms of ecosystem services provision which increased both with decreasing site size and with increasing user participation. Such findings point towards the catalytic potential of small-scale horticulture orientated green space use. Moreover, Dennis et al. (2016b) demonstrated that the distribution of such innovative land-use in the study area represents an adaptive response to specifically low levels of domestic garden cover as opposed to green space. Such work therefore supports the potential significance of smaller cultivated pockets of green space and, in this respect, the influence of domestic gardens highlighted in the analysis echoes the welldocumented benefits to human health issuing from horticultural activities (Hynes and Howe, 2004; Pudup, 2008; Krasny and Tidball, 2015). Furthermore, the particular efficacy of domestic gardens highlighted here provides empirical support bringing together benefits already alluded to in the scientific literature. For example, research has demonstrated separately the links between biological diversity and human well-being (Carrus et al., 2015; Hartig et al., 2014; Marcus and Sachs, 2013; Tzoulas et al., 2007) and the proven potential of a variety of urban garden types to host greater biodiversity than other green space types (Cameron et al., 2012; Goddard et al., 2010; 2013; Lin et al., 2015; Speak et al., 2015; Taylor et al., 2016; Thompson et al., 2003). The findings of this study may be in part the result of such synergy.

The greater degree of synergy exhibited between domestic gardens, as opposed to green space, with the measure of health provides support for conclusions in the associated literature that smaller urban gardens, through the provision of differential recreational opportunities (Francis, 1987) and increased species richness (Dennis and James, 2016a; Speak, 2015) offer greater benefit per unit area to human health than larger green spaces. Parallels can also be drawn with other studies demonstrating greater productivity in terms of ecosystem services associated with smaller sites in collectively managed urban green commons (Dennis and James, 2016b). Moreover, the benefits of community-managed green spaces have been well presented through studies in into civic ecology (Krasny et al., 2014; Krasny and Tidball, 2015; Pudup, 2008) and collaborative natural resource management (Ernstson et al., 2008). Given such evidence and the seemingly greater efficacy of smaller, domestic gardens over green space to buffer against levels of poor health as described in this study, there is a case for the conversion of areas of underproductive green space into networks of smaller, individually or collectively managed gardens. The particular productivity and popularity of urban agriculture (Dennis and James, 2016b; Taylor and Lovell, 2012) presents a conversion to this form of land-use as potentially transformative towards the promotion of local community health (Lautenschlager and Smith, 2007; McClintock, 2010) and social cohesion (Okvat and Zautra, 2011). Such measures may be of particular value in the most urban areas as, following the patterns observed in the current study, urban domestic gardens exhibited double the effect than did green space in the mitigation of poor health in such areas. Moreover, domestic garden cover was lowest in the most urban quartile of the study area where green space was greatly more abundant in terms of area cover person ${ }^{-1}$. As such, there is an argument for greater allocation, or re-considered zonation of residential and communal gardens towards more effective local health promotion.

In urban areas where green space is particularly limited, and where allocation of domestic gardens is not feasible, the conversion of a small percentage of green space to more compact, communally cultivated gardens could provide an alternative to private domestic gardens. Following the reported 
benefits in the literature of such spaces to local communities (Krasny and Tidball, 2015; Okvat and Zautra, 2011; Pudup, 2008), such a re-allocation may reap considerable rewards for local residents. Moreover, smaller pockets of green space have also been shown to engender greater user participation with resulting benefits for biodiversity and associated ecosystem services (Dennis and James, 2016a). The implementation of such a strategy would be highly dependent on local availability of green space however. Moreover, in the most urban areas, green space is not only at its lowest in terms of land cover but also demonstrates the highest variability (Table 1). An effective reinterpretation of publicly accessible land would, therefore, necessitate a highly collaborative, innovative and iterative decision-making process. Ideally, one which acknowledges the geographical and social complexities which affect the distribution, use and cultural significance of green space and gardens in urban areas (Domene and Sauri, 2007).

Furthermore, the nature of the relationship between gardens (domestic or communal) of different types and specific measures of human health and well-being warrant closer attention. The measures adopted in the current study of both green space and domestic garden cover were composite values which drew on and included a range of green land cover types. No distinction was made in the GLUD, for example, between gardens dedicated to horticultural activity and food production or those kept as lawns, or between larger green space types such as amenity or agricultural land. Likewise the health deprivation dataset employed drew on a range of indicators relating to health and well-being, including but not discriminating between, various physical and mental measures of human health. Accordingly, the aggregated nature of these measures precluded a more sophisticated appreciation of the interactions between various naturalistic elements in the landscape and associated human activity with specific indicators of population health (e.g. morbidity, mental health, obesity). Further research is therefore necessary in order to add such detail to an understanding of the specific health outcomes related to proximity and interaction with domestic, communal and public green space types. More effective planning and design of green space provision at various levels of access and formality, targeting specific activities towards unique health promotion goals should, thereby, be facilitated.

In terms of the evidence presented both here and in other works cited however, there exists a strong case for the re-implementation of urban green space planning in terms of both design and management towards a selective emphasis on small-scale horticulture involving stakeholders with limited access to quality green space and gardens.

\section{Conclusions}

The study demonstrated that measures of land-cover by green space, when normalised for local area population, offer an alternative, and valuable interpretation of the effects of naturalistic elements in urban areas. The study thereby provides support for the consideration of local population levels as an important ingredient in urban green space planning. The population-standardised measure adopted herein provided greater explanatory power to the observed effects of green space on health deprivation than previous assessments which have employed land-use data only. As such a similar approach as that demonstrated here could, if adopted by urban planning authorities, help identify areas of greatest need of natural resources more effectively than more general measures of land-use and land cover. In terms of the relative benefits of public and domestic forms of urban green space the latter was consistently more effective as an environmental boon to local well-being and as such presents a compelling case for the integration of urban gardens and gardening opportunities into existing green space design at all stages of the rural-urban gradient. Arriving at a successful strategy through which to implement such a reconfiguration of urban green space into current planning frameworks would require further work in order to evaluate the social-ecological complexities associated with user participation, stakeholder consultation and the decentralisation of local resources. 


\section{References}

Barthel, S., Folke, C. and Colding, J. 2010. Social-ecological memory in urban gardens: retaining the capacity for management of ecosystem services. Global Environmental Change. 20(2): 255-265.

Bird, W. 2007. Natural Thinking: Investigating the link between the Natural Environment, Biodiversity and Mental Health. London: Royal Society for the Protection of Birds.

Bolund, P. and Hunhammar, S. 1999. Ecosystem services in urban areas. Ecological Economics. 29: 293-301.

Burls, A. and Khan, W. 2005. Human health and nature conservation. BMJ. 331: 1221-1222.

Cameron, R., Blanusa, T., Taylor, J., Salisbury, A., Halstead, A., Henricot, B. and Thompson, K. 2012. The domestic garden: its contribution to urban green infrastructure. Urban Forestry and Urban Greening. 11(2): 129-137

Carrus, G., Scopelliti, M., Lafortezza, R., Colangelo, G., Ferrini, F., Salbitano, F., Agrimi, M., Portoghesi, L., Semenzato, P. and Sanesi, G. 2015. Go greener, feel better? The positive effects of biodiversity on the well-being of individuals visiting urban and peri-urban green areas. Landscape and Urban Planning. 134: 221-228.

Clarke, L. and Jenerette, G. 2015. Biodiversity and direct ecosystem service regulation in the community gardens of Los Angeles, CA. Landscape Ecology. 30(4): 637-653.

Coutts, C. 2011. Putting the capital " $E$ " environment into ecological models of health. Journal of Environmental Health. 74(4): 26-29.

Costanza, R., Fisher, B., Mulder, K., Liu, S. and Christopher, T. 2007. Biodiversity and ecosystem services: A multi-scale empirical study of the relationship between species richness and net primary production. Ecological Economics. 61: 478-491.

Costanza, R., Wilson, M., Troy, A., Voinov, A., Liu, S., and D'Agostino, J. 2006. The Value of New Jersey's Ecosystem Services and Natural Capital. NJ. New Jersey Department of Environmental Protection

DCLG (Department for Communities and Local Government). 2010. English Indices of Deprivation 2010 [computer file]. Downloaded from: https://www.gov.uk/government/statistics/english-indicesof-deprivation-2010. Licensed under: https://www.nationalarchives.gov.uk/doc/open-governmentlicence/version/3.

Defra (Department for the Environment, Food and Rural Affairs). 2010. What Nature Can Do for You. London. Defra.

Defra (Department for the Environment, Food and Rural Affairs). 2011. The Natural Choice: Securing the Value of nature. London. Defra.

De Groot, R., Alkemade, R., Braat, L., Hein, L. and Willemen, L. 2010. Challenges in integrating the concept of ecosystem services and values in landscape planning, management and decision making. Ecological Complexity. 7(3): 260-272. 
De Groot, R. S., Wilson, M. A. and Boumans, R. M. J. 2002. A typology for the classification, description and valuation of ecosystem functions, goods and services. Ecological Economics. 41: 393408.

Dennis, M., Armitage, R. and James, P. 2016a. Social-ecological innovation: adaptive responses to urban environmental conditions. Urban Ecosystems. DOI 10.1007/s11252-016-0551-3.

Dennis, M. Armitage, R. and James, P. 2016b. Appraisal of social-ecological innovation as an adaptive response by stakeholders to local conditions: Mapping stakeholder involvement in horticulture orientated green space management. Urban Forestry and Urban Greening. 18: 86-94.

Dennis, M. and James, P. 2016a. User participation in urban green commons: Exploring the links between access, voluntarism, biodiversity and well being. Urban Forestry \& Urban Greening. 15: 2231.

Dennis, M. and James, P. 2016b. Site-specific factors in the production of local urban ecosystem services: A case study of community-managed green space. Ecosystem Services. 17: 208-216.

Domene, E. and Saurí, D., 2007. Urbanization and class-produced natures: Vegetable gardens in the Barcelona Metropolitan Region. Geoforum. 38(2): 287-298.

Epstein, L., Raja, S., Gold, S., Paluch, R., Pak, Y. and Roemmich, J., 2006. Reducing sedentary behavior the relationship between park area and the physical activity of youth. Psychological science. 17(8): 654-659.

Ernstson, H., Sörlin, S. and Elmqvist, T. 2008. Social movements and ecosystem services-the role of social network structure in protecting and managing urban green areas in Stockholm. Ecology and Society. 13(2): 39. Available at: http://www.ecologyandsociety.org/vol13/iss2/art39/

Folke, C., Jansson, Å., Larsson, J., Costanza, R., 1997. Ecosystem appropriation by cities. Ambio. 26: 167-172.

Francis, M. 1987. Meanings attached to a city park and a community garden in Sacramento. Landscape Research. 12(1): 8-12.

Fuller, R., Irvine, K., Devine-Wright, P., Warren, P. and Gaston, K. 2007. Psychological benefits of greenspace increase with biodiversity. Biology Letters. 3(4): 390-394.

Galindo, M. and Corraliza, J. 2000. Environmental aesthetics and psychological wellbeing: relationships between preference judgements for urban landscapes and other relevant affective responses. Psychology in Spain. 4:(1) 13-27.

Gidlöf-Gunnarsson, A. and Öhrström, E. 2007 Noise and well-being in urban residential environments: the potential role of perceived availability to nearby green areas. Landscape and Urban Planning. 83: 115-126.

Goddard, M. A., Dougill, A. J. and Benton, T. 2010. Scaling up from gardens: biodiversity conservation in urban environments. Trends in Ecology and Evolution. 25(2): 90-98. 
Goddard, M. A., Dougill, A. J. and Benton, T. 2013. Why garden for wildlife? Social and ecological drivers, motivations and barriers for biodiversity management in residential landscapes. Ecological Economics. 86: 258-273.

Guitart, D., Pickering, C. and Byrne, J., 2012. Past results and future directions in urban community gardens research. Urban Forestry \& Urban Greening. 11(4): 364-373.

Haines-Young, R. and Potschin, M. 2013. Common International Classification of Ecosystem Services (CICES): Consultation on Version 4, August-December 2012. EEA Framework Contract No EEA/IEA/09/003. Available at: http://www.cices.eu or www.nottingham.ac.uk/cem

Hartig, T., Mitchell, R., de Vries, S. and Frumkin, H. 2014. Nature and Health. Annual Review of Public Health. 35: 207-228.

Hynes, H. and Howe, G. 2004. Urban horticulture in the contemporary United States: personal and community benefits. Acta Horticulturae. 643: 171-181. DOI: 10.17660/ActaHortic.2004.643.21

Jackson, L. 2003. The relationship of urban design to human health and condition. Landscape and Urban Planning. 64(4): 191-200.

Kaplan, S. 1995. The restorative benefits of nature: toward an integrative framework. Journal of Environmental Psychology. 15(3): 169-182.

Kidd, A. 2006. Manchester: A History. Lancaster. Carnegie Publishing.

Kuo, F., Bacaicoa, M. and Sullivan, W. 1998. Transforming inner-city landscapes: trees, sense of safety and preference. Environment and Behavior. 30(1): 28-59.

Kuo, F. and Sullivan, W. 2001. Environment and crime in the inner city: does vegetation reduce crime? Environment and Behaviour. 33: 343-367.

Krasny, M., Russ, A., Tidball, K. and Elmqvist, T. 2014. Civic ecology practices: Participatory approaches to generating and measuring ecosystem services in cities. Ecosystem Services. 7:177-186.

Krasny, M. and Tidball, K. 2015. Civic Ecology: Adaptation and Transformation from the Ground Up. Cambridge, MA: MIT Press.

Lautenschlager, L. and Smith, C. 2007. Understanding gardening and dietary habits among youth garden program participants using the Theory of Planned Behavior. Appetite. 49(1): 122-130.

Lau, S. and Yang, F., 2009. Introducing healing gardens into a compact university campus: design natural space to create healthy and sustainable campuses. Landscape Research. 34(1): 55-81.

Li, D. and Sullivan, W. 2016. Impact of views to school landscapes on recovery from stress and mental fatigue. Landscape and Urban Planning. 148(149-158).

Lin, B., Philpott, S. and Jha, S. 2015. The future of urban agriculture and biodiversity-ecosystem services: challenges and next steps. Basic and Applied Ecology. 16(3): 189-201.

Lottrup, L., Grahn, P. and Stigsdotter, U.K., 2013. Workplace greenery and perceived level of stress: Benefits of access to a green outdoor environment at the workplace. Landscape and Urban Planning. 110: 5-11. 
Maas, J., Verheij, R., de Vries, S., Spreeuwenberg, P., Schellevis, F. and Groenewegen, P. 2009. Morbidity is related to a green living environment. Journal of Epidemiology and Community Health. 63(12): 967-973.

Maas, J., Verheij, R., Groenewegen, P., de Vries, S. and Spreeuwenberg, P. 2006. Green space, urbanity, and health: how strong is the relation? Journal of Epidemiology and Community Health. 60(7): 587-592.

Mace, G., Norris, K. and Fitter, A. 2012. Biodiversity and ecosystem services: a multilayered relationship. Trends in Ecology and Evolution. 27(1): 19-26.

Maller, C., Townsend, M., Pryor, A. and Brown, P. 2006. Healthy nature, healthy people: 'contact with nature' as an upstream health promotion intervention for populations. Health Promotion International. 21(1): 45-54.

Marcus, C. 2007. Healing gardens in hospitals. Interdisciplinary Design and Research e-Journal. 1(1): 1-27.

Marcus, C. and Sachs, N. 2013. Therapeutic Landscapes: An Evidence-Based Approach to Designing Healing Gardens and Restorative Outdoor Spaces. New Jersey: Wiley and Sons.

Marselle, M., Irvine, K. and Warber, S. 2014. Examining Group Walks in Nature and Multiple Aspects of Well-Being: A Large-Scale Study. Ecopsychology. 6(3): 134-147.

McClintock, N. 2010. Why farm the city? Theorizing urban agriculture through a lens of metabolic rift. Cambridge Journal of Regions, Economy and Society. 3(2): 191-207.

Millenium Ecosystem Assessment. 2005. Ecosystems and Human Well-being: Health Synthesis. Washington D.C. Island Press.

Mitchell, R., Astell-Burt, T. and Richardson, E. 2011. A comparison of green space indicators for epidemiological research. Journal of Epidemiology and Community Health. 65(10): 853-858

Mitchell, R. and Popham, F. 2007. Greenspace, urbanity and health: relationships in England. Journal of Epidemiology and Community Health. 61(8): 681-683.

Niemelä, J., Saarela, S., Söderman, T., Kopperoinen, L., Yli-Pelkonen, V.,Väre, S. and Kotze, D. 2010. Using the ecosystem services approach for better planning and conservation of urban green spaces: a Finland case study. Biodiversity and Conservation. 19(11): 3225-3243.

Okvat, H. and Zautra, A. 2011. Community gardening: a parsimonious path to individual, community, and environmental resilience. American Journal of Community Psychology. 47(3-4): 374-387.

ONS (Office for National Statistics). 2001 Census: Aggregate data (England and Wales) [computer file]. UK Data Service Census Support. Downloaded from: http://infuse.mimas.ac.uk. Licensed under the terms of the Open Government Licence [http://www.nationalarchives.gov.uk/doc/opengovernment-licence/version/2]. 
(ONS) Office for National Statistics. 2005. Generalised land use database statistics for England [computer file]. London. Downloaded from:

http://data.gov.uk/dataset/land_use_statistics_generalised_land_use_database.

ONS (Office for National Statistics). 2016. Super Output Area (SOA) - ONS. [online] Available at: http://www.ons.gov.uk/ons/guide-method/geography/beginner-s-guide/census/super-outputareas--soas-/index.html [Accessed 4 Feb. 2016].

Orsini, F., Gasperi, D., Marchetti, L., Piovene, C., Draghetti, S., Ramazzotti, S., Bazzocchi, G. and Gianquinto, G. 2014. Exploring the production capacity of rooftop gardens (RTGs) in urban agriculture: the potential impact on food and nutrition security, biodiversity and other ecosystem services in the city of Bologna. Food Security. 6(6): 781-792.

Perrins-Margalis, N., Rugletic, J., Schepis, N., Stepanski, H. and Walsh, M. 2000. The immediate effects of a group-based horticulture experience on the quality of life of persons with chronic mental illness. Occupational Therapy in Mental Health. 16(1): 15-32.

Pretty, J., Peacock, J., Sellens, M. and Griffin, M. 2005. The mental and physical health outcomes of green exercise. International Journal of Environmental Health Research. 15(5): 319-337.

Pudup, M. 2008. It takes a garden: cultivating citizen-subjects in organized garden projects. Geoforum. 39(3): 1228-1240.

Radford K. and James P. 2013. Changes in the value of ecosystem services along a rural-urban gradient: A case study of Greater Manchester, UK. Landscape and urban planning. 109(1): 117-27.

Söderback, I., Söderström, M. and Schälander, E., 2004. Horticultural therapy: the 'healing garden'and gardening in rehabilitation measures at Danderyd Hospital Rehabilitation Clinic, Sweden. Pediatric rehabilitation. 7(4): 245-260.

Speak, A., Mizgajski, A. and Borysiak, J. 2015. Allotment gardens and parks: provision of ecosystem services with an emphasis on biodiversity. Urban Forestry and Urban Greening.

http://dx.doi.org/10.1016/j.ufug.2015.07.007

Stott, I., Soga, M., Inger, R. and Gaston, K. 2015. Land sparing is crucial for urban ecosystem services. Front Ecol Environ. 3(7): 387-393.

Sullivan, W. and Chang, C. 2011. Mental health and the built environment. In: Dannenberg, A., Frumkin, H. and Jackson, R. eds. Making Healthy Places. Island Press/Center for Resource Economics. Washington DC, pp. 106-116.

Sullivan, W. Kuo, F. and DePooter, S. 2004. The fruit of urban nature - vital neighborhood spaces. Environment and Behavior. 36(5): 678-700.

Taylor, A., Kuo, F. and Sullivan, W. 2002. Views of nature and self-discipline: evidence from inner city children. Journal of Environmental Psychology. 22(1-2): 49-63.

Taylor, J., Lovell, S., Wortman, S. and Chan, M., 2016. Ecosystem services and tradeoffs in the home food gardens of African American, Chinese-origin and Mexican-origin households in Chicago, IL. Renewable Agriculture and Food Systems. 1-18. 
TEEB (The Economics of Ecosystems and Biodiversity). 2008. An Interim Report. Wesseling. European Communities.

Thompson, K., Austin, K., Smith, R., Warren, P., Angold, P. and Gaston, K. 2003. Urban domestic gardens (I): Putting small-scale plant diversity in context. Journal of Vegetation Science. 14(1): 71.

Thompson, C., Roe, J., Aspinall, P., Mitchell, R., Clow, A. and Miller, D., 2012. More green space is linked to less stress in deprived communities: Evidence from salivary cortisol patterns. Landscape and Urban Planning. 105(3): 221-229.

Tyrvainen, L. 2001. Economic valuation of urban forest benefits in Finland. Journal of Environmental Management. 61(1). 75-92.

Tzoulas, K., Korpela, K., Venn, S., Yli-Pelkonen, V., Kaźmierczak, A., Niemelä, J. and James, P. 2007. Promoting ecosystem and human health in urban areas using Green Infrastructure: a literature review. Landscape and Urban Planning. 81(3): 167-178.

United Nations, Department of Economic and Social Affairs. 2007. World Urbanisation Prospects: 2007 Revision. New York. United Nations.

UK NEA (United Kingdom National Ecosystem Assessment). 2011. UK National Ecosystem Assessment: Understanding Nature's Value to Society. London. UK NEA.

Von Shirnding, Y. 2002. Health and sustainable development: can we rise to the challenge? The Lancet. 360(9333): 632-637.

Wall, D. and Nielsen, U. 2012. Biodiversity and ecosystem services: is it the same below ground? Nature Education Knowledge. 3(12): 8.

Ward Thompson, C., Aspinall, P. and Roe, J. 2014. Access to Green Space in Disadvantaged Urban Communities: Evidence of Salutogenic Effects Based on Biomarker and Self-report Measures of Wellbeing. Procedia - Social and Behavioral Sciences. 153: 10-22.

WHO (World Health Organisation). 2005. Ecosystems and Human Well-Being: Health Synthesis. Geneva. WHO.

Woods, L., Rachet, B., Riga, M., Stone, N., Shah, A. and Coleman, M. 2005. Geographical variation in life expectancy at birth in England and Wales is largely explained by deprivation. Journal of Epidemiology and Community Health. 59(2): 115-120. http://doi.org/10.1136/jech.2003.013003 